\title{
Blurring Focalization: Psychological Expansions of Point of View and Modality
}

\author{
Joaquín Martínez Lorente \\ Universidad de Murcia
}

\begin{abstract}
This paper revises how the expansion of analysis beyond the classic perceptual facet creates problems in narratological models of focalization. The difficulties in maintaining the original ideals of "grammatical" objectivity and typological neatness are illustrated by the comparatively more problematic (or less satisfactory) reductiveness of the attempts to implement psychological distinctions. The possibility of applying Fowler's "mindstyle" and Lindemann's "mindscape", as well as more sophisticated typologies using modality (Simpson's and Doležel's) are discussed. The analytical problems raised are illustrated by a methodologically oriented study of a story by Graham Greene ("I Spy").
\end{abstract}

We have been given classifications and descriptions which leave us wondering why we have bothered to classify and describe (Booth Distance 60)

Introducing one's incursions into areas of inquiry about which such skeptical attitude was expressed so long ago (even before Genette!) is, understandably enough, an arduous task, because of the pervading feeling of stagnation and the many conventional requirements that have to be met. In the field of point of view, for instance, three commentaries or tasks have become standard: one is expected (a) to specify and organise the lexical variants of the concept; (b) then to laboriously disentangle the plethora of roughly-equivalent-yetdifferent-and-leading-to-confusion distinctions that have been developed, and to denounce the undesirable effects of this situation (Genette Figuras III, Nouveau Discours. Bal. Fowler Linguistics and the Novel, Linguistic Criticism; Chatman Story and Discourse, 
Characters and Narrators. Rimmon-Kenan. Toolan. Simpson); (c) finally, to propose some "theoretical refinements" (Nelles 365), since internal contradictions have been detected or because the specific problems posed by a particular text cannot be solved. In this context of continuous reworking and uncertain progress it is not striking to read, for instance, that "a major revision is in order" (Edmiston 729), or to find a list of nine recent refinements of Genette's focalization and still the claim that "most of these critics have misanalyzed certain key aspects of Genette's original conception of focalization and that as a result their discussions are based on, and sometimes compromised by, a set of false premises about it" (Nelles 365). Genette himself perceived the provisional quality of his findings (Figuras III 322); however, to accept an evolutionary conception of any discipline is not as serious as the tensions caused in models by refinements and expansions, which operate in two directions: "improvements" shake the basic tenets of the area of inquiry to which they are applied, but the interests of the area of inquiry also condition the application of those improvements (perhaps even to the point of distortion).

These issues will occupy me: 1) The study will show the tensions inflicted on narratological models by the contraction of point of view into focalization, and the more recent expansion of typological efforts towards psychological ingredients. ${ }^{1}$ 2) I will illustrate the former with a revision of some attempts at integrating modality in point of view on the psychological plane. 3) These attempts to develop complementary insights will be practically assessed (or rather illustrated) with a particular application; that is, with their ability to cope with Graham Greene's use of point of view in a short (just over 1,100 words) masterpiece entitled "I Spy." Recalling Booth's opening words, "classifications and descriptions" will be constantly defeated by Greene's story, but Greene's "victory" will be best observed with the help of those tools. ${ }^{2}$

\section{Changes of Name and Size: Continuing Conflicts.}

As the title advances in a slightly cryptic way, I will argue that the terminological "point of view/focalization" debate and the incorporation of discriminations of several facets have stimulated the continuity of some theoretical conflicts and problems already present, but less evident, in original formulations. The specific problem to concentrate on is the treatment of the psychological facet in perception-oriented studies on focalization.

1.1 "Point of view" or "focalization"? These are obviously not the only NAMES available: the dichotomy sanctions the existence of two major traditions - Anglo-American studies on "point of view" (Friedman) and Genette's narratological category of "focalization" (Figuras III). Genette's coinage is intended to discriminate between two aspects assimilated in the American scene: perspective ("who sees?," the imaginary "position" that determines how/what events are perceived) and narration ("who speaks?," the "identity" of the telling voice, which does not necessarily coincide with the identity of the agent whose position has been chosen to select information). Thus the two traditions depend on the will to assimilate or distinguish the categories of mode and voice. ${ }^{3}$ Genette's original intervention has been very influential, but not passively followed:

a) A technical problem is the persistence of some degree of heterogeneity in Genette's list of types of focalization - zero or non-focalized, internal, external - a distinction 
precisely justified by Genette for its homogeneity: "Genette's classification is based on two different criteria: while the distinction between non-focalized and internally focalized refers to the position of the perceiver (the focalizer), that between internally focalized and externally focalized refers to the perceived object" (Rimmon-Kenan 139).

b) The figure of the focalizer derives from Mieke Bal's revision of Genette's theory. Her revision is also made in the name of homogeneity, because it seeks to more decisively distinguish between the "who speaks?" and "who sees?" sides of the traditional notion of point of view by exploring the two logical positions in any process of focalization focalizer/focalized. Another necessary step in the institution of the category of focalization is the separation of the level of story (in which the focalizer is situated) from that of the text (in which the narrator appears). But apart from these figures we have still to decide what to do with authors (both implied and real): according to Bal's opponents (and this includes Genette's revision of Nouveau Discours) it is difficult to justify the focalizer, a "theoretical middle ground between the narrator and the actor.... There is no advantage to eliminating the implied author in order to give its functions to the newly created focalizer" (Nelles 372-3). ${ }^{4}$

c) Critics are always expected to explain their choice of new names for the concepts they develop. In the case of focalization Genette has been preoccupied with the "opticalphotographic connotations" of point of view, and with the uncertain persistence of the connotation despite his choice of the comparatively more abstract focalization (Genette Figuras III 244, Rimmon-Kenan 71). For instance, Chatman thinks that

Genette has always seemed to mean more by focalisation than the mere power of sight. He obviously refers to the whole spectrum of perception: hearing, tasting, smelling, and so on. What is not so clear is the extent to which he means it to refer to other mental activity, like cognition, and to functions other than mental" (Chatman Characters and Narrators 192). And further evidence is provided by Toolan, whose alternative proposal shows his concern with a restrictive treatment of the concept: "I do think orientation is a usefully wider, less visual, term than focalization, and would help us to remember that 'cognitive, emotive and ideological' perspectives, in addition to the simply spatiotemporal one, may be articulated by a narrative's chosen focalization" (68). The "undesirable" association of focalization with a visual dimension is partly Bal's responsibility, who defends focalization as a technical category "used in photography and film" (102); besides, her "perceptual slant" (Deleyto 160) is undeniable. This approach has been criticized, because it reveals a "predisposition to read the text as if it were a sequence of camera shots in a film" (Nelles 375).

The three intersecting problems I have revised could be easily related to two contradictory aspirations of narrative theory - to create theoretical distinctions and to explain each category as self-consistent, independent, and complete. Genette original distinction is only incompletely realized, as it still combines different phenomena- the "angle(s) of seeing" in relation to the fictional world, the object "seen" (both objects and people), and the consciousness that "sees"; the problems of Bal's focalization are comparable because the theoretical layer stipulated for focalization - story-can only apparently be grasped as independent from other facets which constitute the complex 
phenomenon of narrative mediacy: "identity and non-identity of the realism of the fictional characters and of the narrator (first-/third-person narration); internal and external perspective (limited point of view/omniscience); teller-character and reflector-character as agents of transmission (telling/showing)" (Stanzel Teller-Characters 5).

However, I would like to explore a more restricted side of the problem: the notion of perception represents the history of focalization, as attempts to transcend a simplistic, purely visual interpretation of perception (the movement towards "conception") have led to the loss of typological neatness of models of focalization. Bal's rejection of a visual sense of perception illustrates both the movement and the induced uncertainty: "Perception ... is a psychological process, strongly dependent on the position of the perceiving body; a small child sees things in a totally different way from an adult, if only as far as measurements are concerned. The degree to which one is familiar with what one sees also influences perception.... Perception depends on so many factors that striving for objectivity is pointless" (100). There is in this commentary an interesting blend of "objective" references to observational-physical-visual details and assumptions about mental processes derived from them, about how things are "seen" in a deep sense. ${ }^{5}$ But Bal's vindication of perception as also made of psychological factors is not the only one identified by critics and attributed to focalization, because others have added an ideological dimension, and to complicate things a bit, similar expansions have been assigned to the apparently rejected notion of point of view from the area of Critical Linguistics. In general terms there is broad agreement on a three-term scheme-spatiotemporal, psychological, ideological-but it has given rise to interesting variations: Fowler (Linguistics and the Novel 76) describes two classes - perspective and attitude-, apparently equivalent to Mieke Bal's physical and psychological (101) points of perception. Chatman's perceptual and conceptual are also comparable, but he adds an heterogeneous interest (Story and Discourse). ${ }^{6}$ Uspensky's three levels are further distinguished in Toolan's previous commentary, which follows Rimmon-Kenan (79-82) in representing the cognitive and the emotive as two branches of the psychological facet: this leaves four kinds, or even five, if we consider how space and time are ruled differently (Rimmon-Kenan 77-9. Fowler Linguistic Criticism. Simpson). To sum up: ${ }^{7}$

\begin{tabular}{||c|c|c|c||}
\hline $\begin{array}{c}\text { Uspensky } \\
\text { Fowler 1986 } \\
\text { Simpson }\end{array}$ & spatiotemporal & psychological & ideological \\
\hline Rimmon-Kenan & perceptual & emotive cognitive & ideological \\
\hline Chatman 1978 & perceptual & conceptual & interest \\
\hline Fowler 1977 & perspective & attitude \\
\hline Bal & perspective / focalization / perception & \\
\cline { 2 - 4 } & physical & psychological \\
\hline
\end{tabular}


1.2 The chart reveals that these critics are not faced with a merely lexical issue, but with the SIZE of focalization, with the borders of focalization and the meaning of perception: although we are constantly reminded that "perception must be understood in such a sense that it may include an agent's world view (ideology, conceptual system, Weltanschauung, etc.)" (Deleyto 161), the perceptual facet tends to be identified with perspective (in a sensory sense) and with the spatiotemporal dimension, and opposed to conception, attitude, the psychological, emotive, cognitive, ideological, etc.. Therefore the ingredients of Bal's "conceptualized" perception are generally distinguished, and the perceptual sticks to a "visual," factual sense.

One factor to consider is that some of these critics are working with facets of "point of view," and others with facets of focalization, which is a more restricted category in a different theoretical frame. How does this affect the grasping of the contents of perception and the feasibility of the extension of the typological methods of narratological research in the spatiotemporal dimension of focalization to more "subjective" areas? Perhaps the simplification of focalization, its restriction to perception in strict sensory bounds could be a good methodological strategy, because it would eliminate some analytical difficulties involved in assimilating the psychological component of perception in focalization. In order to decide on the necessity of that strategy we should revise the practice and methods of narratology. In section 1.2.1 I will comment on the tendency of narratological studies to impose an overarching distinction between the internal and the external on all facets (Rimmon-Kenan 75-7), and on its superior effectiveness when its classifications have been restricted to the spatiotemporal facet and to the perceptual factor. In section 1.2.2 I will describe the selective appropriation of the psychological and ideological facets, and its treatment of subjectivity and interiorization.

\subsubsection{The paradoxical objectivity of the spatiotemporal dimension.}

The spatiotemporal dimension, connected with the perceptual in its most physical sense, has been left in a paradoxical position. It has the strength of its "self-explanatory" quality (Simpson 11), and deictic examples are usually preferred to illustrate focalization, not only because the existence of verbal indications of proximity or situation is more objectively observed than the other dimensions, but also because theoretically it lends itself to less confusion: the constituents of the focalizer's sensory range can be more easily discriminated than those of its mind and emotions. It is easier to decide what could have been seen or heard by a character than to determine (or measure) to what extent information has been processed by his/her mind, or to what extent another superimposed focalization (the narrator's) intervenes. In this sense, when the question "who sees?" has been enlarged to mean "who thinks?," "who feels?," "who evaluates?," "who interprets?," etc., elucidation has become extremely complicated, since vision and mental attitude, the ingredients of "extended" focalization, can be attributed to different simultaneous focalizers, in much the same way as the voice of narration can be combined with a different source of vision.

A good example is precisely provided by Bal's treatment of the "who speaks?"/"who sees?" distinction. The idea that one person can tell a story from another person's vision 
is illustrated with a sentence from Henry James' The Ambassadors ("Elizabeth saw him lie there, pale and lost in thought"). Bal claims that it is ridiculous to think that the second part is narrated by Elizabeth: "What this sentence does is to present Elizabeth's vision clearly: after all, she does see him lying down" (101). All right, it is clear that she "saw him" and that she is not narrating the second part, but it is clear that the "saw him" part has a different quality of obviousness (and that is why it is emphasised by Bal!) from the relatively more problematic issue of the source of the evaluation of his state ("pale and lost in thought"), which implies psychological activity and subjectivity. It is true that these commentaries can be very easily attributed to the focalizer and "perceived" in the focalized, because of their comparatively visual quality. However, we could imagine the effects concerning determination in terms of the internal/ external opposition (so dear to narratologists) of the substitution of "pale and lost in thought" with, for instance, "bored and irritated": these adjectives imply a greater deal of interpretation, and more decisively allow for the possible existence of an external focalizer or subjectivity making this interpretation or "shaping" Elizabeth's observations. ${ }^{8}$

Other technical and practical sides of the problem can be signalled: we can explicitly apply it to the theoretical level -story - to which focalization is ascribed by Bal. In this respect a serious technical problem is how mental activities or ideological positions can be described at the intermediate level of story and attributed to a focalizer without being conditioned by the fact that they are grasped through the level of the text, that the narrator's language may convey a different "mind" from the focalizer's own: "It is almost impossible to speak without betraying some personal 'point of view', if only through the very language used" (Rimmon-Kenan 72). This problem is more serious "when the focalized is also human, his own subjectivity is no less relevant than that of the focalizer" (Rimmon-Kenan 80). A third, more practical contradiction arises from the contrast between focalization as a more or less distinct theoretical possibility and normal creative practice, which reveals the diversity of factors confusingly assimilated: "lo que llamamos focalización interna raras veces se aplica de forma rigurosa. En efecto, el propio principio de ese modo narrativo entraña en rigor que el personaje focal no aparezca descrito jamás ni designado desde el exterior, y que el narrador no analice objetivamente sus pensamientos ni percepciones.... La focalización interna no se realiza plenamente sino en el relato en 'monólogo interior"' (Genette Figuras III 247). It is evident that, strictly speaking, the typological possibility called "internal focalization" involves several different phenomena, that the postulation of a single label and then the unwilling concession that narrators have naturally to depart from this internal position is contradictory, because at least two kinds of internal focalization should be identified: the choice of a character as a deictic centre, and access to the character's mind. To these a third kind of "internal" method can be identified, but this belongs to the level of narration, and has to be disentangled from focalization proper -i.e., to narrate by copying his/her thoughts or using a combined or external method (the possibility of "copying" the character's language belongs to this level). Let us simply remember Bal's remark: "Perception depends on so many factors that striving for objectivity is pointless" (100). The paradox of the spatiotemporal facet of focalization lies in the contrast between the methodological appeal of its objective distinctions and its inevitable "imperfect" imitation 
when it is applied to explain the "superior" facets of psychological and ideological focalization, those that exhibit subjectivity. In the following subsection I will revise two theoretical notions associated to focalization in the psychological and ideological facets.

\subsubsection{Psychological Mindscapes and Ideological Mind-styles: Difficult Applications.}

Psychological focalization is typically approached in an "objective" way, which reveals a tendency to assume that cognition means "amount of information": Focalization literally addresses matters of cognition alone.... The only question to be resolved in the determination of focalization is how much the narrator tells the narratee about the story in relation to the characters' knowledge about the story" (Nelles 366. Italics mine). Obvious problems are apparent if we consider this statement: cognition also involves the processing of events, but this psychological area has to be left aside, since it requires analytical tools narratology is perhaps not prepared to implement, or psychology to provide. What is offered, instead, is a grammaticized version of the psychological phenomena narrated involved in narrative, one in which all the strength is attributed to the external-internal dichotomy: "

In cognitive terms, the external-internal opposition becomes one between unrestricted and restricted knowledge. In emotive terms, it distinguishes between attitudes that are objective, neutral or uninvolved, on the one hand, and attitudes that are subjective or involved, on the other. All these facets pertain only to the focalizer" (Edmiston 736). ${ }^{9}$

This treatment of the psychological plane is a local manifestation of a general "syntactic" tendency of narratological studies: the main consequence of the narratological concern with the articulation of the "narrating" on the "narrated" in the field of focalization is the generation of typologies that determine the implicit manipulation of the "fabula" as detected in the "story" layer. The reductiveness of the narratological approach to the psychological facet could be overcome with the implementation of findings derived from the area of psychology, since the structure of mental processes can affect the structure of focalized narratives. This is attempted, for instance, by Lindemann's mindscapes: on the evidence of a narrative text with constant shifts of interior monologues not announced by any narrator, he imagines a hypothetical notion of mindscape, "a particular landscape of knowledge" (205) or cognitive system organizing perception of the world. Lindemann suggests that each mindscape has three kinds of elements: a) those activated by knowledge, b) those derived from the "webs of connections that hold among knowledge items", and c) "the particular array of inferences and presuppositions ... valid against the background of a) and b)" (193-4). Lindemann's proposals ere too provisional and dependent on a concrete text, but the gap between psychology and literary studies is bridged, since they are formulated with a pragmatic-linguistic orientation. He shows a strong interest in the systematic formal procedures involved: "presuppositions and the related concepts of entailment, implication, implicature are grammatical contrivances to implement a mindscape in an actual text surface" (204). 
Cognitive psychology itself could play a decisive role in the study of focalization. Theoretically speaking, we should rely on the research done by psychologists to describe the psychological facet of point of view, to increase the amount of information about the mental processing of events by focalizers, and the proper analysis of the elements signalled above would require a very high standard of competence in psychological research. However, this higher degree of competence has not been reached in the prominent interdisciplinary work carried out so far. ${ }^{10}$ There is a significant breach between the goals of psychologists dealing with the cognitive aspects of literary narratives and the analysis of cognitive processes proposed by Lindemann to elucidate textual mindscapes, because in the former the cognitive "factor" is primarily located in the "external" domain of readers who experience literary texts. The cognitive phenomena examined are, for instance, processes of activation of "working memory" or "long-term memory," "on-line" and "offline" inferences, etc., and the emphasis is sometimes severely quantitative ("statistical readers," "potency" of interpretation understood as popularity in numerical terms, proposed tasks as measuring literary effects, etc. Dixon et al.). As can be inferred from the previous parameters the vein of these studies is segregationist, because literariness is still essentially attributed to texts, and opposed to "unliterariness." Literariness of narratives is naively identified with notions as "depth of appreciation," i.e. the degree of improvement of one's opinion of a text after a second reading (Dixon et al. 17). For instance, the relevance of this kind of work can be illustrated with Keith Millis' study on the issue of "perspective": the basic concept -"deictic center" (Bruder et al.)-derives from well-known distinctions in narrative studies:

The deictic center is the convergence of spatial (WHERE), temporal (WHEN) and character (WHO) information at any point within the narrative. WHO refers to the character that is in current focus... Bruder et al. distinguish between two types of WHO: the focal WHO and the focalizing WHO. The focal WHO is the character that the reader tracks in space and in time, whereas the focalizing WHO is the agent of a character's experience. The focal WHO would roughly correspond to an external perspective, whereas the focalizing WHO would roughly correspond to an internal perspective. (Millis 238-9)

However, the critical information contained in the second part of the extract is unproblematically accepted by Millis, who concentrates on a different issue: to show experimentally how readers update perspective in a rigid internal/external binary, i.e., how they perceive shifts in deictic center, and not to explore the formal means that convey those changes, nor the exact significance of shifts in the structure of the narrative story used in the experiment. To sum up, psychological paraphernalia are not used to describe the psychological processes represented in narrative, and their likely symptomatic. ${ }^{11}$

Similar methodological problems can be observed when we consider the application of stylistic research to the ideological facet of point of view, reflected in the notion of mind-style: borders between the ideological and the psychological are far from distinct, because both facets fall within the same general notion of "attitude," and the individual's mind is the locus of worldview. The ideological facet is defined in a stylistic context as 
"any distinctive linguistic presentation of an individual mental self" (Fowler Linguistics and the Novel 103): "consistent structural options, agreeing in cutting the presented world to one pattern or another, give rise to an impression of a world-view, what I shall call a 'mind-style'. In the novel, there may be a network of voices at different levels, each presenting a distinct mode of consciousness" (Fowler Linguistics and the Novel 76). The strong psychological flavour is confirmed by Fowler's references to M.A.K. Halliday's analysis of William Golding's The Inheritors, where an internal method of point of view is used to represent the cognitive limitations of Lok, the Neanderthal hero: this illustrates the idea that "a writer may create a narrator, or a character, whose language expresses a characteristic or idiosyncratic point of view" (Linguistic Criticism 133). Despite the mental-psychological connotation, it is clear for Fowler that mind-style's genuine theoretical ground is the ideological: "[mind-style is] the world-view of an author, or a narrator, or a character, constituted by the ideational structure of the text. From now on I shall prefer this term to the cumbersome 'point of view on the ideological plane' which I borrowed from Uspensky ... the notions are equivalent" (Linguistic Criticism 150). If Fowler's previous statement does not suffice, any psychological quality in the traditional narratological fashion dissolves when we consider the stylistic emphasis: the ideological facet explores the relationship between an individual and his environment as reflected in linguistic choices at different levels. In this sense mind-style can be relevant for the analysis of narrative method, since language is a useful symptom for the identification of the mind (i.e. world-view) from which the story is told.

In this section I have tried to show some ingredients of the implementation of new perspectives on focalization -the identification of three facets and the vindication of a more conceptual notion of focalization- but I have concentrated on how the multiple descriptive uses of the spatiotemporal, psychological and ideological have been problematically forced into (or annexed to) the syntactic goals of narratological study, resisting the radical selection of the original choice of focalization. Some problems remain unsolved, as, for instance, the elucidation of the figure of the focalizer in relation with those of the implied author and the narrator. This is specially clear in the handling of subjectivity, and particularly in the special resonance of the narrator's subjectivity in narratives using an internal focalization technique. In the following section I will show a parallel situation, revealed by the incorporation of a modal perspective to typologies of focalization.

\section{Modality in Point of View: the Necessity of Modal Worlds.}

Modality has been applied in the frame of point of view on the psychological plane (Fowler Linguistics and the Novel, Linguistic Criticism. Simpson) to develop a broader (more complete, less dependent on visual aspects), deeper (more relevant to psychological aspects such as the feelings and thoughts experienced by focalizers) view of focalization. The declared theoretical source of this modal expansion is systemic-functional linguistics and stylistics. In narratological terms it joins Bal's levels of story and text, as the classical internal/external opposition in focalization is complemented with an analysis of the narrator's style to convey it, which generates a superimposed internal/external (or 
narrator's intermediate absence/presence). The formal tool selected is modality: "the grammar of explicit comment, the means by which people express their degree of commitment to the truth of the propositions they utter, and their views on the desirability or otherwise of the states of affairs referred to" (Fowler Linguistic Criticism 131. Simpson 39).

Roger Fowler (Linguistic Criticism 134) supplements the classic distinction between an internal and an external position with respect to action or characters with two other possibilities, which derive from the presence or absence of marks of modality: modality is foregrounded with the presence of "verba sentiendi" - "words denoting thoughts, feelings and perceptions" (Simpson 39). Their effect is to convey the impression of a definite, subjective, personality expressing itself in relation to the narrated substance, provoking "strangement," 12 while the absence of these verba suppresses the impression of a separate consciousness mediating between events and the reader, i.e., blurs the textual trace of an external subjective focalization. The practical outcome of Fowler's double choice is a catalogue of four possibilities:

\begin{tabular}{|c|c|c|c||}
\hline TYPE & PERSPECTIVE & MODALITY & DESCRIPTION \\
\hline A & internal & foregrounded & first person \\
\hline B & internal & absent & omniscient authorial \\
\hline C & external & absent & impersonal neutral \\
\hline D & external & foregrounded & external speculative \\
\hline
\end{tabular}

Paul Simpson's more recent proposal of a "modal grammar" opens with a positive revision of Fowler's model, specially the necessity of the concept of modality, but he holds that "a stylistician working with this model might find some problems" (51-2). Simpson's reworking consists of three main operations: A) Four modal systems are identified, which represent non-linguistic concepts: the deontic expresses duty, obligation and commitment; the boulomaic reflects desire; the epistemic expresses knowledge, belief and cognition; and, finally. the perception system. B) The traditional internal-external distinction is replaced by two asymmetrical distinctions, yielding three possibilities: category A narratives are homodiegetic; category $\mathrm{B}$ are heterodiegetic. The latter are then divided into Narratorial mode ("from a 'floating' viewing position." Simpson 55), and Reflector mode (when the telling voice moves "into the active mind of a particular character." Simpson 55). C) Each of the three previous possibilities is subdivided on the pattern of three broad patterns of modality, rather arbitrarily called "positive," "negative," and "neutral." The logic underlying these distinctions and labels is simple: the presence of linguistic formulae expressing deontic and boulamic systems are "positive," and reflect the narrator's subjective evaluation and involvement. Conversely, the presence of markers of epistemic and perception systems are "negative," and their effect is alienating. It is assumed that the presence of markers of the positive type (deontic, boulomaic) precludes the appearance of 
markers of the other type, and viceversa. In "neutral" varieties categorical assertions take precedence over modalized expressions. The chart is a summary of Simpson's (75):

\begin{tabular}{|c|c|c|c|}
\hline \multirow{2}{*}{\multicolumn{2}{|c|}{ Category A homodiegetic }} & positive & "co-operative" \\
\hline & & negative & distancing effect \\
\hline \multirow{6}{*}{$\begin{array}{c}\text { Category B } \\
\text { heterodiegetic }\end{array}$} & \multirow{3}{*}{ Narratorial mode } & macitive & oninions and iudrement \\
\hline & & negative & narrator tries to make sense of story \\
\hline & & neutral & narrator refuses privileged access \\
\hline & \multirow{3}{*}{ Reflector mode } & positive & character's position. Opinions. \\
\hline & & negative & $\begin{array}{l}\text { strangement in the mind of character. } \\
\text { Double focalization }\end{array}$ \\
\hline & & neutral & viewing position of passive character \\
\hline
\end{tabular}

Our previous discussion of narratology's selective psychology is relevant again: Fowler's and Simpson's typologies incorporate modality as another means of further discriminating between different degrees of focalization, by measuring the narrator's mental (cognitive or emotive) position in relation to action. Introducing deontic, boulomaic modality, etc. explains the problem of the focalizer's involvement or knowledge of the story in a more sophisticated, but similar, vein than in narratology. These proposals could be negatively assessed because of the excessive formalism of the search of formal marks of modality or because of the lack of harmony between the wholehearted reliance on an exclusive internal/external (or narratorial/reflector) opposition, and the relatively impressionistic determination of modality. However, I will comment on the problem this model shares with those described in the previous section: there I showed that the expansion of narrative point of view into psychology/ideology has made the adjustment of findings more clearly strained and reductive, because narration always contains or betrays another superimposed subjectivity, another point of view. My proposal in this section is that it is very difficult to assume that the implementation of a modal perspective can be satisfactorily carried out if the exclusivity of the grammatical approach to focalization is preserved, because dealing with indications of desire, duty, etc, as mere marks of epistemic "strangement" or emotional "involvement" in the area of focalization is equally restrictive. Once these factors are introduced in the analysis it is difficult not to see that the modal significance of narrative action itself, of the "narrated" interferes in the analysis of the modality of the "narrating."

What is needed, perhaps, is to complement and articulate models of modality with another modal system that explains how stories are built (and analysed) on these 
parameters. Such an important incorporation of modality is present in Doležel's proposal of narrative modalities, "global (macrostructural) semantic constraints ... global restrictions imposed on the possible courses of narrated actions" (Narrative Worlds 543). In order to characterize narrative coherence Doležel selected a set of modal narrative worlds, characteristically ruled by principles that organize fictional action, or make it follow certain courses or foreground specific conflicts or contrasts:

a. In alethic worlds actions are organized according to the modalities of possibility, impossibility, and necessity. This modality allows for a rigorous analysis of devices of construction and authentication of fictional worlds, and for distinctions between natural, supernatural, and intermediate (i.e., mythological, fantastic, ambiguous) worlds (548-551).

b. In deontic worlds the significance of actions derives from the modalities of permission, prohibition, and obligation; actions are classified as prohibited/permitted (failure to perform an action imposed as obligation is obviously equivalent to prohibited action), and logically lead to strings as violation-punishment or fulfillment-reward (544).

c. In axiological worlds the modalities of goodness, badness, and indifference, actions are prompted by values (desires) and dysvalues (repulsions); two realms can generate these assignments of value: a supraindividual codex (codexal) or an individual (relativized): "The existence of relativized modalities brings narrative agents into mutual modal relationships. If their relativized modalities are identical we will say that the agents are in the state of modal concord. If their relativized modalities are contrary (or, at least, different), we will speak about modal discord between narrative agents. It can be assumed that modal concord will lead to stories of alliance (cooperation), whereas modal discord to stories of conflict" (545).

d. Knowledge, ignorance and belief are the modalities of epistemic worlds, so typical of mystery stories, whose modal base is "the transformation of ignorance (or false belief) into knowledge" (545).

Doležel's modality, proposed in an "extensional" frame, is expected to supplement the grammar of narrative action with a systematization of the possible contents prevailing in fictional worlds, but we could also consider its relevance to complement focalization, to help it make more sense. However, it would be also helped itself, it would make more sense, because it would correct a "weakness" of Doležel's model: the lack of concern with the transforming or conditioning power of modalized discourse over modal substance. How is the modal type of a narrative determined? The answer from extensional semantics is that the substance of the story makes it a natural decision: "modal constraints [are] imposed in the particular worlds" (Doležel Narrative Worlds 544. My italics). This statement relies on a classic conception of narrative technique, because it accepts an unquestioned, reliable, neutral and omniscient narrator who does not influence, who does not modalize the story and of the world, the kind of external narrator the effects of whose focalization, understood as "restriction," is quite negligible. The modal nature of a narrative text is the (implied) author's responsibility only in the sense that this external agent modalizes the story by selecting events with a particular modal nature. Doležel's model could then be said to be insufficient, but also necessary, to understand point of view on the psychological plane. The marks of modality "contained" in fictional worlds or stories are also information to be included in any model designed to describe modality in 
psychological point of view. Of course a similar claim could be made to justify any author's selection of a particular focalization device on the spatiotemporal plane: for instance, in "whodunit" stories the range of possibilities of focalization "activated" (all the agents who have "seen" anything) are organized in such a way that suspense is created and the identification of the murderer-criminal is delayed (see Bal 114-5); it is undeniable that there is always interaction between the quality of the story and the type of focalization used in the story, and effects are achieved because the grammar of point of view has been coordinated with "the quality of the story." How ever, it seems to me that the necessity of interaction in the case of modality and the psychological facet is still more manifest, because it is more difficult to isolate the orientation (significance) of the story -the modal interpretation normally attributed by readers to actions - from the orientations possibly privileged by the focalizer, the narrator, or the implied author, especially since the identities of these figures cannot be easily disentangled.

The strength of the theoretical necessity of an articulation of intensional and extensional models will occupy me in the next section, but I will not predict any combined theoretical model. Instead, I will represent the issue as an analytical problem and as a property of texts with an interesting aesthetic potential. I have summarized it with the question "who modalizes?" and it is well illustrated by the ambiguities of Greene's story; my analysis will show: 1) that serious descriptive problems arise when modal theories of point of view are not complemented with the kind of extensional semantic perspective offered by Doležel, that the application of modality in narrative theories of focalization should be appended (articulated) with a semantic perspective using the modal approach; 2 ) that the theory of modality and point of view reflected in Greene's story (see note 2 above) demands the combination of information about the modal qualities of the narrated story and the modality of the narrative method. The aesthetic principle favoured by the text's theory foregrounds and makes highly functional the combination of these two sources.

3. Who/What focalizes/modalizes in Greene's "I Spy"? Story Structure and Focalization.

\section{0 "I Spy." The text.}

Charlie Stowe waited until he heard his mother snore before he got out of bed. Even then he moved with caution and tiptoed to the window. The front of the house was irregular, so that it was possible to see a light burning in his mother's room. But now all the windows were dark. A searchlight passed across the sky, lighting the banks of cloud and probing the dark spaces between, seeking enemy airships. The wind flew from the sea, and Charlie Stowe could hear behind his mother's snores the beating of the waves. A draught through the cracks in the window-frame stirred his night-shirt. Charlie Stowe was frightened.

But the thought of the tobacconist's shop which his father kept down a dozen wooden stairs drew him on. He was twelve years old, and already boys at the County School mocked him because he had never smoked a cigarette. The packets were piled twelve deep below, Gold Flake and Player's, De Reszke, Abdulla, Woodbines, and the little shop lay under a thin haze of stale smoke which would completely disguise his 
crime. That it was a crime to steal some of his father's stock Charlie Stowe had no doubt, but he did not love his father; his father was unreal to him, a wraith, pale, thin, indefinite, who noticed him only spasmodically and left even punishment to his mother. For his mother he felt a passionate demonstrative love; her large boisterous presence and her noisy charity filled the world for him; from her speech he judged her the friend of everyone, from the rector's wife to the "dear Queen", except the "Huns", the monsters who lurked in Zeppelins in the clouds. But his father's affection and dislike were as indefinite as his movements. Tonight he had said he would be in Norwich, and yet you never knew. Charlie Stowe had no sense of safety as he crept down the wooden stairs. When they creaked he clenched his fingers on the collar of his night-shirt.

At the bottom of the stairs he came out quite suddenly into the little shop. It was too dark to see his way, and he did not dare touch the switch. For half a minute he sat in despair on the bottom step with his chin cupped in his hand. Then the regular movement of the searchlight was reflected through an upper window and the boy had time to fix in memory the pile of cigarettes, the counter and the small hole under it. The footsteps of a policeman on the pavement made him grab the first packet to his hand and dive for the hole. A light shone along the floor and a hand tried the door, then the footsteps passed on, and Charlie cowered in the darkness.

At last he got his courage back by telling himself in his curiously adult way that if he were caught now there was nothing to be done about it, and he might as well have his smoke. He put a cigarette in his mouth and then remembered that he had no matches. For a while he dared not move. Three times the searchlight lit the shop, as he muttered taunts and encouragements. "May as well be hung for a sheep", "Cowardy, cowardy custard," grown-up and childish exhortations oddly mixed.

But as he moved he heard footfalls in the street, the sound of several men walking rapidly. Charlie Stowe was old enough to feel surprise that anybody was about. The footsteps came nearer, stopped; a key was turned in the shop door, a voice said: "Let him in," and then he heard his father, "If you wouldn't mind being quiet, gentlemen. I don't want to wake up the family." There was a note unfamiliar to Charlie in the undecided voice. A torch flashed and the electric globe burst into blue light. The boy held his breath; he wondered whether his father would hear his heart beating, and he clutched his nightshirt tightly and prayed, "O God, don't let me be caught." Through a crack in the counter he could see his father where he stood, one hand held to his high stiff collar, between two men in bowler hats and belted mackintoshes. They were strangers.

"Have a cigarette," his father said in a voice dry as a biscuit. One of the men shook his head. "It wouldn't do, not when we are on duty. Thank you all the same." He spoke gently, but without kindness: Charlie Stowe thought his father must be ill.

"Mind if I put a few in my pocket?" Mr Stowe asked, and when the man nodded he lifted a pile of Gold Flake and Players from a shelf and caressed the packets with the tips of his fingers.

"Well," he said, "there's nothing to be done about it, and I may as well have my smokes." For a moment Charlie feared discovery, his father stared the shop so thoroughly; he might have been seeing it for the first time. "It's a good little business," he said, "for those that like it. The wife will sell out, I suppose. Else the neighbours'll be wrecking it. Well, you want to be off. A stitch in time. I'll get my coat."

"One of us'll come with you, if you don't mind," said the stranger gently.

"You needn't trouble. It's on the peg here. There, I'm all ready." 
The other man said in an embarrassed way, "Don't you want to speak to your wife?" The thin voice was decided, "Not me. Never do today what you can put off till tomorrow. She'll have her chance later, won't she?"

"Yes, yes," one of the strangers said and he became very cheerful and encouraging. "Don't you worry too much. While there is life ..." and suddenly his father tried to laugh.

When the door had closed Charlie Stowe tiptoed upstairs and got into bed. He wondered why his father had left the house again so late at night and who the strangers were. Surprise and awe kept him for a little while awake. It was as if a familiar photograph had stepped from the frame to reproach him with neglect. He remembered how his father had held tight to his collar and fortified himself with proverbs, and he thought for the first time that, while his mother was boisterous and kindly, his father was very much like himself, doing things in the dark which frightened him. It would have pleased him to go down to his father and tell him that he loved him, but he could hear through the window the quick steps going away. He was alone in the house with his mother, and he fell asleep.

\subsection{The deictic dimension: spatiotemporal focalization and perception.}

This third-person narration is clearly built on the choice of Charlie Stowe's physical perspective; the structure of the story is made to coincide with his experience. Concerning the spatiotemporal facet, the story opens with the boy in bed and ends in the same place, when the boy falls asleep. We could say that there is a story because the boy decides to make this nightly expedition, or, more precisely, because he is "there" awake and downstairs when his father comes in with the strangers; in other words, because he is there to focalize. Of course the fact that the narration is in third person does not change anything; anyway, we could say that, strictly speaking, the narrating voice physically focalizes the boy, who in turn focalizes all the other objects and events, but at the theoretical level of the story this narrating voice is irrelevant. This personal perspective, this "deictic center" is consistently kept when references to events outside the strict temporal frame of the story are made: 1) The boy's motivation for tonight's conduct is having being mocked at school. Boys have mocked at him and we have to suppose that he has heard them. 2) His parents and their behaviour appear in the story as images perceived by Charlie and experienced by him in this moment. There is nothing about them that has not been seen by him. This dimension has consequences in Charlie's disaffections (he "left even punishment to his mother") and explain (or modulate) the boy's attitude to his "crime." 3) His father announcement about going to Norwich that night is part of the boy's experience, fears and surprise. In other words, all information external to the spatiotemporal frame of the story is "here" because it has been spatiotemporally perceived by the boy. This principle is followed even when we consider the specifics of the spatial dimension, the amount of information that can be visually obtained by the boy is considered, and carefully complements the information he can hear: he learns the position of cigarettes (and we see them) thanks to the "searchlight"; when the boy is hidden in the shop, he has a look (and we too) at the adults' movements and gestures "through a creak in the counter." 
3.2 The psychological dimension (1): narration and the emergence of another subjectivity.

Greene's story coincides with Charlie's experience also in a psychological sense. Taking focalization in the original, objective Genettian sense of "restriction of field" (Figuras III 245), the narrator has limited what can be told in the area of cognition and emotions, in the area of inner life, to only one of the many agents of the story; it is fixed internal focalization (Figuras III 245) or type B (heterodiegetic) technique in the Reflector mode (Simpson 55) because it is character-bound, and bound exclusively to this character, not to any other. Besides, we have numerous indications of the boy's cognitive limitations (the war context is not linked by him to his personal world, and specially to his father's) and of his mental processing of his experiences: "waited until he heard," "was frightened", "the thought ... drew him on", etc. Although in third person, it is easy to imagine these commentaries as formulated (i.e. perceived) by the character, and they pass the test suggested by Barthes for the personal mode - "rewriting" them in first person does not alter our perception of the source of commentaries or experiences (Genette Figuras III 247-8).

However, the way of looking at the psychological facet of point of view these classifications reveal - the narrator tells/knows what Charlie thinks and not what other agents think- although objective and unproblematic, is superficial and inadequately "quantitative." Besides, it is restrictive and very artificial, because some problems frequently overlooked when dealing with spatiotemporal focalization become more prominent when applied to the psychological, intellectual or cognitive realm. For instance, how the focalizer is also focalized and how mental perspectives and operations are always contaminated. Small details in Greene's story like the "creak in the counter" invite us to think of focalization in a literal sense, with Charlie's eyes as a camera recording what can be told, and this image supports the impression that Charlie is a "pure" and exclusive focalizer. However, if we remember Genette's commentaries on the practical improbability of internal focalization (see end of section 1.2.1 above), the very beginning of Greene's story "Charlie Stowe ..." confirms the impression that even at a physical level Charlie is simultaneously focalized and focalizer: he is described and designated. Only because there is not contradiction or contrast between what the "eyes" of the external focalizer (who follows Charlie) and Charlie's eyes we tend to simplify the analysis by omitting the external focalizer and Charlie's being a focalized.

But how does this logic fare in the area of Charlie's inner life? Theoretically speaking internal focalization excludes mediation in our access to the focalizer's inner life or mental activity; it implies that we can isolate the focalizer's subjectivity and his/her grasping of the reality surrounding him/her. As we will see in these pages, this is not the case in Greene's story, because Charlie is a psychological focalizer of his reality, but he is simultaneously a psychologically focalized in various ways, and in the text we read an amalgam of two subjectivities: Charlie's psychological life has been interpreted by another subjectivity, one that has summarised, organized and evaluated Charlie's "motivation," "affection," "attitude to his crime," "fear and surprise," although merely by "wording" them. Genette also speaks of objective analysis ("analice objetivamente"). However the ideas of objectivity and analysis are extremely difficult to determine in this context, 
because we cannot always decide to what extent internal focalization (Charlie's thoughts) includes unacknowledged analysis "embedded" in narrative discourse) ${ }^{13}$ For instance we can consider the statement "Surprise and awe kept him for a little while awake.... $\mathrm{He}$ remembered how his father had ... fortified himself with proverbs". Can we assume that this is a direct "transcript" of Charlie's consciousness? To what extent has he conceptualized his surprise and awe? To what extent is he aware that his father's purpose is to dispel fear? Despite the possible irrelevance of this information, these sentences reveal that some external focalizer is incorporating his own values and interests, subjectivity in ambiguous, undecidable ways.

This dimension, which has been only occasionally alluded to by critics, cannot be easily interpreted by following the traditional typological efforts: $:^{14}$ it rather reveals the existence of a scale of possibilities in the description of psychological observations that is not clearly resolved in the "knowledge" " absence of knowledge" binary of narratological theory, because not all commentaries require the same amount of interpretation or introspective power on the part of the narrator, and also because the boy's mental processes and products exhibit several degrees of development, reflexivity, intentionality, and sophistication, ranging from "elaborated" analytical deliberation to spontaneous instinctive impression. The focalizer's mental processes are not clearly organized in an internal/external, reflector/narratorial binary, but arranged in an extremely complex scale of intermediate possibilities. These internal possibilities range from almost "factual" statements that "conceal" the figure of the narrator and reduce him to a linguistic position ("waited until he heard," "Charlie was frightened") to statements of uncertain authorship, in which we can detect the presence of "autonomous" interpretative operations, the presence of particular interests that cannot be always automatically attributed to the focalizer. This last possibility is suggested by commentaries like:

the thought of the tobacconist's shop which his father kept down a dozen wooden stairs drew him on. He was twelve years old, and already boys at the County School mocked him because he had never smoked a cigarette.

It is not at all clear to what extent the force to go downstairs is perceived by the boy as an impulse or as a deliberate meditation, but a more important problem is that of deciding if the boy's having been mocked is part of his thoughts at the moment. We could think that the boy remembers his schoolmates's laughing at him to encourage himself; however, the commentary sounds like an adult, objective summary of the event, a justification of his behaviour. We could think of a mere interpretative act connecting the two sentences (then still part of internal focalization), but also consider it a narratorial (or authorial) decision to introduce the theme of manhood. To attribute this commentary to one or another source is important to decide whether we are dealing with focalization, if we accept Edmiston's commentary: "A distinction must be made between what the narrator can perceive and what he chooses to reveal, and the latter does not concern focalization" (731). Comparable observations can be made if we consider the following statement: 
a thin haze of stale smoke which would completely disguise his crime. That it was a crime to steal some of his father's stock Charlie Stowe had no doubt, but he did not love his father; his father was unreal to him.

The concept of crime is described as an evaluation of the incident, and Charlie could share it, but this impression is not favoured by the style of narration. A similar shade of uncertainty is present in the justification ("but he did not love his father"), because to simply attribute this reflection to the boy (and exclude any element of mediation by the narrator) is not convincing (it could be a simple device to give the reader a piece of information the reader will need later on). These instances of ambiguity should suffice to propose that an heterodiegetic internal point of view, a reflector mode, never completely conceals or precludes the appearance of a separate consciousness organizing and orienting commentaries. In Greene's story we have such a figure of an independent and active "focalizing mind" coexisting with the focalizer Charlie, and makes his mind, simultaneously rather than alternatively, a focalized and a focalizer. These uncertain statements concerning the "source" of reflections and connections coexist in the other end of the scale with other instances in which the narratorial stance is more decisively expressed and assumed, i.e. while Charlie's mind is responsible for his affections and fears, some commentaries on Charlie's age and intellectual development are the narrator's responsibility: "in his curiously adult way", "grown-up and childish exhortations oddly mixed", "Charlie was old enough to feel surprise." These statements undeniably belong to the narratorial mode because they cannot possibly derive from Charlie's thoughts. Besides, it is a curious blend of the narratorial and the internal, because these commentaries are scarce and scrupulously restricted to Charlie's psychological dimension, and quite objective. In fact, the notion of restriction is important to explain one important structural principle of Graham Greene's story. The issue dealt with by the narrator's commentaries, the problem thematized by the narrator - Charlie's "restricted" age- is also revealed through a technique that foregrounds the problem of Charlie's knowledge, the nature of his affections and their evolution as caused by his age and its limitations. The problem, to discuss in the following section, is whether this technique belongs to what critics call focalization and modalization, or what notion of focalization we need to cover Greene's technique.

I have emphasised some "impurities" of Greene's technique to show how his impure internal technique reflects the theoretical problems of typologies of focalization. As far as the intrinsic poetics of focalization of Greene's story is concerned, we have seen that different degrees of narratorial "psychological" or intellectual involvement or activity (not simply perceptual access!) in the rendering of Charlie's inner life are combined with others in which the narratorial responsibility is more formally, but still to some extent uncertainly, acknowledged. In other words, the neatness of the theoretical distinction between narratorial and reflector modes very easily collapses in practice, because (taxonomically) undesirable phenomena as double focalization and ambiguous focalization are not at all marginal exceptions but the inescapable norm, and elucidation is broadly impressionistic. This is specially clear in this psychological dimension, when we consider 
the many traces (and degrees) of the narrator's psychological intervention, i.e. the uncertain superposition of the narrator's and the focalizer's mindscapes. ${ }^{15}$

\subsection{The Psychological Dimension (2): Childhood, Strange Conversations and Modality.}

In the previous section we have assumed an inevitable "other" focalizer that brings tension to the analytical simplifications of structuralist-oriented narratologists. At least to explain Greene's practice the traditional selective omniscience technique (Friedman) could be perhaps a more intelligent and competent category, precisely because of its heterogeneity: we institute a narrator who more or less faithfully represents Charlie's consciousness, but does not make himself prominent as narrator (or as author). The difficulties of focalization are important if we consider another fact about Greene's story: there is a moment in the narrative in which the reader feels s/he has to generate an "autonomous" interpretation, and it is also felt that something about the adult world is not understood by the hidden witness Charlie. The necessity of generating this autonomous interpretation is due to a restriction in the text, one that is not so dramatically perceived in the first part of the story. If we remember Edmiston's previous commentary, we have to decide whether this is a problem of focalization - restriction of field - or simply a narratorial omission of information. Should we first determine whose responsibility is the missing information -the focalizer's because beyond his scope or the narrator's because he prefers not to tell it-in order to declare whether focalization is or is not involved here? Apparently the answer is not difficult if we remember that the narrator's commentaries on Charlie's age focus on an aspect considered paradigmatic in classic studies on point of view (Booth Rhetoric of Fiction 47-9) and focalization: fixed internal focalization is illustrated by Genette with Henry James' What Maisie Knew. In James' story we are told of events of an adult story through the experience and perception of a girl who cannot understand what is happening. The paradigmatic quality of childhood to explain psychological focalization has been already shown in this study with Bal's choice of children to explain the psychological dimension of perception, and it is not a coincidence that Bal also selects Maisie to introduce internal focalization, or character-bound focalization:

... a character-bound focalizor ... brings about bias and limitation. In Henry James' What Maisie Knew the focalization lies almost entirely with Maisie, a little girl who does not understand much about the problematic relations going on around her. Consequently, the reader is shown the events through the limited vision of the girl, and only gradually realizes what is actually going on. But the reader is not a little girl. S/he does more with the information $\mathrm{s} / \mathrm{he}$ receives than Maisie does, $\mathrm{s} / \mathrm{he}$ interprets it differently. Where Maisie sees only a strange gesture, the reader knows that $\mathrm{s} / \mathrm{he}$ is dealing with an erotic one. (104-5)

The reference to a limited vision and the reader gradually realizing what is actually going on seems to make application inevitable, but we have the narrator's commentaries on Charlie's mental development, in which by calling the reader's attention to Charlie's interpretative weaknesses, the narrator "announces" the section of the story in which 
Charlie's cognitive limitations are more evident; i.e., an external focalizer explicitly warns about a future transition into an internal focalizer, and Charlie becomes a focalizer (witness) after having been simultaneously focalizer and focalized. The mechanism is extremely interesting because until then readers, "satisfied" with the information they have been given about Charlie did not notice this double role: readers perceived the world in terms of Charlie's inner life and the narrator's interventions were easily assimilated as springing from him. And still another interesting explanation using descriptive tools related to focalization is that when Charlie witnesses - perceives - the adult conversation readers are forced to start processing - conceptualizing - it independently.

An important test to confirm the pertinence of the internal focalization category could be provided by the analysis of the modal markers. Assuming that the heterodiegetic reflector mode is the dominant technique, Charlie's interpretative problems should be well represented by the presence of modal markers of the epistemic system, those classified by Simpson as making the negative type. It is undeniable that a note of epistemic strangement is communicated in this section of the story, but we have to decide whether: a) they are genuinely attributable to Charlie's defective perception of events (or more precisely defective or absent conceptualization), b) they depend on the narrator's (deficient or absent) perception of Charlie's mind, c) both focalizers are epistemically stranged, that is, with epistemic strangement imposed on double focalization, or, d) none of them is modally marked, strangement is due to a mere absence of narratorial explanation about the event. While the boy's apistemic strangement clearly smooths the enormous emotional intensity of the situation of the adults and transforms the conversation into a riddle, it is more difficult to decide the focal source of the commentaries annexed to direct speech: Charlie's father is constantly characterised through references to the tone of his voice - "a tone unfamiliar," "undecided voice," "voice dry as a biscuit," "spoke gently but without kindness"- and the same applies to the strangers - "gently," "embarrassed," "decided," "cheerful," "encouraging." These commentaries are ambiguous concerning their source, as can be observed by comparing them with a more explicit remark as "Charlie Stowe thought his father must be ill". This last sentence obviously comments on Charlie's poor interpretative faculties, but we cannot say that in the previous instances there is focalization in the sense of alteration or deformation of information because of lack of intellectual competence, in Maisie's way (as commented by Bal about erotic movements not identified by the girl). Commentaries on the tones and moods of the voices are those we expect in a person who is alien to the background of the conversation, but they are quite precise and they require a certain degree of adult interpretation. In short, the uncertain identity of the focalizing source makes the type of modality and the relevance of focalization also uncertain:

1. If the boy is the one processing the emotions associated to the voices the passage from perception into conception is initiated, or perhaps completed, but not to the point of allowing the boy to put all the pieces together, to interpret them - to identify and understand his father's problem. However, this very last stage of the intellectual processing of the situation cannot be said to be, strictly speaking, a problem of focalization.

2 . If the narrator is the source of commentaries on moods betrayed by words, we cannot speak of epistemic strangement, at least if we use Simpson's description, which 
concentrates on "double focalization" in a reductive fashion. Simpson's emphasis and examples (Kafka's The Trial) are unfair in Greene's text, because a basic distinction has to be established between the narrator's unlimited knowledge of Charlie's mind and Charlie's extremely limited knowledge of his father's inner life. There is no negative modality concerning the narrator's power, and his/her refusal to explain what has escaped Charlie's attention "does not concern focalization."

The presence and possible application of these signs of strangement yields important information about the text. In this respect modality can be useful to describe focalization, but not following Simpson's sequential and taxonomic logic, where a more or less impressionistic distinction is added to a previous apparently "neat" distinction between reflector and narratorial modes. Modality is simply another category that can practically perform functions equivalent to those of modes of narration, and not so clearly a supplementary distinction realized on top of an "unproblematic" reflector/narratorial binary.

Modality has an important role to play in focalization, but as one in a range of equivalent possibilities of communicating effects derived from restrictions of knowledge, different motivations, etc., and one, again, not restricted to Simpson's or Fowler's grammatical approaches: the introduction of the modal perspective has to be coordinated with (because it is significant in the context of) the intrinsic modal quality of the story, following Doležel's typology. In this respect, an extensional approach to modal systems has much to say about Greene's story, because elements of the deontic, axiological and epistemic systems are present in the "substance" of the story:

a) DEONTIC: A forbidden action, performed by the boy, is not detected, while the father's forbidden actions have been detected by the strangers. There is an important emotional orientation in the narration of this modality, because the boy's fears and anxiety are systematically emphasised.

b) AXIOLOGICAL: The prohibition is based on the goodness/badness of actions, but also on the boy's affective dimension, his shifting alliances with his parents: these change from the mother to the father, but also from a supraindividual codex (the official patriotic language of his mother), to a relativized, private and secret one, from discord to concord in relation with his father, "doing things in the dark which frightened him."

c) The EPISTEMIC is also problematic and significant, one connected with the issue of psychological growth: there is a movement in Charlie's consciousness from complete ignorance into incomplete knowledge about his father, and also towards superior knowledge about himself. This last movement is paradoxical, because Charlie's increased sense of identity is motivated by external pressure (act of maturity induced by others) and leads to identification with his father.

Many effects (or ironies) of the story can be explained with these ingredients: Charlie's movement into spiritual concord with his father is articulated with his lack of understanding of the events perceived. Another aspect is added to this, since the boy moves from spiritual loneliness (with his mother) into spiritual company with his father, but this is ruined by the physical loneliness (with his mother) announced at the end of the story. 
4. Conclusion.

No level of refinement is likely to help us adapt the model for a thoroughly rigorous analysis or classification of entire narratives. (Nelles 371)

It is the fate of most neat distinctions in literary theory to be refuted at least by some literary texts. (Stanzel Teller-Characters 12)

The history of focalization has been one of continuous reworking and improvement, although hardly accumulative from consolidated analytical possibilities, because in the movement from the perceptual (visual) to the conceptual the continuity of methods has been particularly difficult. Nelles' and Stanzel's commentaries opening this section seem to focus on the apparent insufficiency of original models when faced with creative practice (especially for the elucidation of internal focalization in heterodiegetic narration); however, a new insufficiency should also be considered -the loss of neatness of models when some improvements (eg. modality) have been uncertainly appended to the original dichotomies. My goal has been to show not only some of the difficulties of the evolution of focalization (the practical marginalization of mind-styles, mindscapes, etc.), but the analytical consequences of the introduction of modality. It has been revealed that the grammatical tendency of original distinctions cannot be easily imitated in the frame of these expansions: modality, for instance, cannot be easily adapted to the role an internal subcategory of the ambiguous, heterogeneous amalgam of technical possibilities focalization has become in its complex history of expansions and contractions. This portrait of the tensions and problems of the models as they develop does not preclude an invitation to apply as many analytical possibilities as can be found useful (for instance modality from the standpoint of extensional narrative semantics), but to correct some restrictive tendencies of narratological theories of point of view.

\section{Notes}

1. My title plays with Nelles' formula "getting focalization into focus". It also recalls Jackson Barry's "expansion of narrative theory" (295) but my interests are opposite to his: Barry complains about "appropriations" of narrative by psychologists, while I am concerned with the application of psychological inquiry in narrative studies. The expansion can be described as a movement from a perceptual perspective to a conceptual one, or, in another context, as the attempts to incorporate extensional semantic distinctions into the syntactically organized frame of narratology, i.e., to grammaticize them.

2. Two notes: a) the first correction ("illustrated" instead of "assessed") implies that a radical, naive instrumentalist option is rejected; b) "use" of point of view is understood as "implicit theory": every text generates (or possesses) its own relevant set of point of view distinctions. In consequence, available typologies of point of view are constantly challenged by the typologies "built" in texts. 
3. The geographical reference to an Anglo-American domain appears in Rimmon-Kenan (71), not in Genette's description: his choice of "focalization" is inspired by "focus of narration" (Brooks-Warren). Among those who use "point of view" as a global concept Genette mentions Lubbock, E.M. Forster and Booth (Rhetoric of Fiction), but also Stanzel (Narrative Situations). In recent contributions to Poetics and Poetics Today focalization is more usual and more debated. Thus, we could think of an alternative chronological, not geographic, contrast (after vs. before Genette), but "point of view" is still the object of many English stylisticians and critical linguisticians (Fowler Linguistics and the Novel, Linguistic Criticism. Leech-Short, Simpson) who are evidently aware of Genette's distinction.

4. The implied author figure is also rejected by Genette, but the inevitability of the narratorauthor figure controlling everything makes Chatman (Characters and Narrators 195) remind that heterodiegetic narrators, often identified as focalizers, do not see or perceive the stories: they simply narrate them.

5. These difficulties are well reflected a few lines later: "I shall refer to the relations between the elements presented and the vision through which they are presented with the term focalization. Focalization is, then, the relation between the vision and that which is 'seen,' perceived." Significantly enough, in the Spanish edition the term "vision" appears as "concepción."

6. This category recalls the also ambiguous notion of "importance," in which intensional and extensional approaches are also opposed. Shen offers a clear revision of the tradition.

7. Strict comparison is impossible: labels are used with different degrees of precision and different positions, and uncertain equivalences are suggested. Besides, there are specific problems: the absence of an explicit "ideological" label in some authors (Chatman, Fowler Linguistics and the Novel, Bal) makes uncertain the applicability of the "conceptual" and "attitude" labels to cover this theoretical space. Fowler's "attitude" can be assigned to the ideological dimension, but no analogous extension can be applied to Bal's psychological perception. The extension of Chatman's "conceptual" area to encompass the ideological one is unclear. Simpson (43) suggests that "spatiotemporal point of view ... might be more appropriately regarded as a subsystem of point of view on the psychological plane."

8. Bal's practical examples and analyses of focalization reveal a predilection for "visual" perception and taxonomic precision: in the revision of levels of focalization the most complex particular example identified - ambiguous focalization - does not go beyond a very factual remark from a text by Chekhov $(1977,119)$. When a higher degree of interiorization is shown in the examples for analysis, in the section on the focalized, we are told about different degrees of interpretative activities on the part of focalizers, but the texts are relatively simple, since both are consistently written in a method of internal focalization. The other analytical "anomaly" in the model is double focalization, which always tends to confusingly combine perceptual and psychological restrictions.

9. The importance of this axis (internal/external) parallels one problem recently denounced by Doležel, who detects "a dualism typical of traditional narratology: action is in the physical domain, character is a set of mental properties (traits, dispositions). In other words, narrative structure is split into physical story and psychological personage" (Thematics of Motivation 62). This dualism is also present in the institution of two narrative traditions - action-based and character-based (Chatman Story and Discourse 118). This dichotomy, however, is far from balanced, as the Aristotelian inspiration of narratological studies gives primacy to plot; in turn, this favours treatments of point of view based on knowledge of facts and the articulation of narrative sequences on the logic of suspense. 
10. Some representative instances are, in an order of decreasing generality, Kintsch-Van Dijk, Van Dijk on the general foundations of text comprehension; Harker, Cupchik, Dixon et al., GioraShen, and Gerrig-Bernardo on several aspects of literary processing and interpretation; HaberlandtGraesser and Kintsch on knowledge and its components in discourse comprehension; Graesser $e t$ al. on inferences in narrative text comprehension. The arguments against these approaches are comparable to those used by Green to attack some applications of pragmatics to literature in general.

11. The psychological approach to the literary could more substantially benefit from some applications of genuinely psychological studies on human acting, as Doležel's application of "a neobehavioristic taxonomy of motivations" (sensory, curiosity, affiliative, aggressive, achievement, power, and independence systems) (Thematics of Motivation 60). This is used to elaborate a preliminary list of possible thematizations of human action in narrative.

12. But, as Simpson comments: "It is worth adding that verbs which represent straightforward mental processes do not de facto constitute part of the perception modal system. Statements of the sort $I$ saw the game or $I$ heard the noise are simply categorical assertions presenting observations on the part of the speaker" (51).

13. This does not depend on the grammatical person (first/third) chosen, because even in homodiegetic narration there is not identity between the subjectivities of the protagonist and the narrator; homodiegetic narration in the present is the only technique that precludes the splitting of the identity of the character-narrator.

14. The only tool that could handle the combination of focalizations, as we saw in the previous section, is a blend of semantic and psychological analysis that would produce means of describing mental operations and their formal articulation.

15. The notion of transition could be instrumental in the description of the combined, "impure" practices I have shown, but this possibility does not theoretically preclude the necessity of identifying the many classes of focalization that could improve the ideal of a simple narratorialreflector dichotomy. Besides, very long texts are normally defined as internal or external, without any general rule explicitly prescribing how one mode "dominates" (a quantitative method?).

\section{Works Cited}

Bal, Mieke. Narratology. 1977. Toronto: Toronto UP, 1984.

Barry, Jackson. "Narratology's Centrifugal Force: A Literary Perspective on the Extensions of

Narrative Theory." Poetics Today 11 (1990): 295-307.

Booth, Wayne. The Rhetoric of Fiction. Chicago/London: U of Chicago P, 1961.

(1961).

. "Distance and Point of View: An Essay in Classification." Essays in Criticism 11

Brooks, Cleanth, and Robert Penn Warren. Understanding Fiction. 1943. Englewood Cliffs: Prentice-Hall, 1979.

Chatman, Seymour. Story and Discourse. Ithaca: Cornell UP, 1978.

. "Characters and Narrators: Filter, Center, Slant and Interest-Focus." Poetics Today

7 (1986): 189-204.

Cupchik, Gerald C. "Component and Relational Processing in Aesthetics." Poetics 22 (1993): 171183.

Deleyto, Celestino. "Focalisation in Film Narrative." Atlantis 13 (1991): 159-177. 
Dixon, Peter, et al. "Literary Processing and Interpretation: Towards Empirical Foundations." Poetics 22 (1993): 5-33.

Doležel, Lubomir. "Narrative Worlds." Sound, Sign and Meaning: Quinquagenary of the Prague Linguistic Circle. Ed. L. Mateijka. Ann Arbor: Michigan Slavic Publications, 1976. 542-52. . "A Thematics of Motivation and Action." Thematics. Ed. Bremond, C., J. Landy, and T. Pavel. Albany: State U of New York P, 1995. 57-66.

Edmiston, William. "Focalization and the First Person Narrator: A Revision of the Theory." Poetics Today 10 (1989): 729-744.

Forster, Edward Morgan. Aspects of the Novel. 1927. Harmondsworth: Penguin, 1963.

Fowler, Roger. Linguistics and the Novel. London: Methuen, 1977.

. Linguistic Criticism. Oxford: Oxford UP, 1986.

Friedman, Norman. "Point of View in Fiction: The Development of a Critical Concept." PMLA 70 (1955): 1160-84.

Genette, Gerard. Figuras III. 1972. Barcelona: Lumen, 1982.

. Nouveau discours du recit. Paris: Seuil, 1983.

Gerrig, Richard, and Allan B.I. Bernardo. "Readers as Problem-Solvers in the Experience of Suspense." Poetics 22 (1994): 459-472.

Giora, Rachel, and Yeshayahu Shen. "Degrees of Narrativity and Strategies of Semantic Reduction." Poetics 22 (1994): 447-458.

Graesser, Arthur, Murray Singer, and Tom Trabasso. "Constructing Inferences During Narrative Text Comprehension." Psychological Review 101 (1994): 371-395.

Green, Keith. "Relevance Theory and the Literary Text: Some Problems and Perspectives." Journal of Literary Semantics 22 (1993): 207-217.

Greene, Graham. “I Spy.”. 1930. Collected Short Stories. Harmondsworth: Penguin, 1986. 147-9. Haberlandt, Karl, and Arthur Graesser. "Component Processes in Text Comprehension and Some of their Interactions." Journal of Experimental Psychology 114 (1985): 357-374.

Halliday, M.A.K. "Linguistic Function and Literary Style: An Inquiry into the Language of William Golding's The Inheritors." Literary Style: A Symposium. Ed. S. Chatman. New York: Oxford UP, 1971.

Harker, W. John. "Information Processing and the Reading of Literary Texts." New Literary History 20 (1989): 465-481.

Kintsch, Walter. "The Role of Knowledge in Discourse Comprehension: A ConstructionIntegration Model.” Psychological Review 95 (1988): 163-182.

Kintsch, Walter, and Teun A. Van Dijk. "Toward a Model of Text Comprehension and Production." Psychological Review 35 (1978): 363-394.

Leech, Geoffrey, and Michael Short. Style in Fiction. London: Longman, 1981.

Lindemann, Bernard. "Readers and Mindscapes." Journal of Literary Semantics 22 (1993): 186206.

Lubbock, Percy. The Craft of Fiction. 1921. New York: Viking, 1963.

Millis, Keith K. "Encoding Discourse Perspective During the Reading of a Literary Text." Poetics 23 (1995): 235-253.

Nelles, William. "Getting Focalization into Focus." Poetics Today 11 (1990): 365-382.

Rimmon-Kenan, Slomith. Narrative Fiction. Contemporary Poetics. 1983. London: Routledge, 1988.

Shen, Yeshayahu. “On Importance Hierarchy and Evaluation Devices in Narrative Texts.” Poetics Today 6 (1985): 681-698.

Simpson, Paul. Language, Ideology and Point of View. London: Routledge, 1993. 
Stanzel, Franz K. Narrative Situations in the Novel. 1955. Bloomington: Indiana UP, 1961. Today 2 (2): 5-15.

Toolan, Michael J. Narrative. A Critical Linguistic Introduction. London: Routledge, 1989.

Uspensky, Boris. A Poetics of Composition. Berkeley: U of California P, 1973.

Van Dijk, Teun A. "Cognitive Processing of Literary Discourse." Poetics Today 1 (1979): 143159. 